"Clandestinités ", Sigila. Revue transdisciplinaire franco-portugaise sur le secret, (GRIS-France, Paris), 19, printemps-été 2007, 235 p., ISSN : 1286-1715 (courriel : <sigila@club-internet.fr>, site : <www.sigila.msh-paris.fr>).

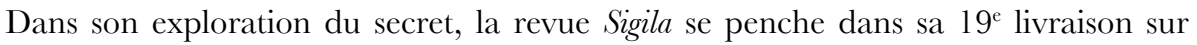
les clandestinités. Témoignages, articles, entretiens, poèmes, chansons, recensions de livres restituent différents volets de ce phénomène, à plusieurs époques et dans différents contextes. Trois textes traitent plus spécifiquement de l'aire lusophone. Le premier est le témoignage de l'ancien président de la République portugaise, Mário Soares. S’il affirme d'emblée que «clandestin, je ne l'ai jamais été » (p. 19), il narre l'action cachée et publique qu'il a menée sous la dictature salazariste. Néanmoins, Mário Soares ne livre aucun ... secret et ce qu'il écrit a déjà été publié ailleurs ${ }^{1}$. Ensuite, le célèbre médiéviste portugais, José Mattoso, décrit la résistance des habitants de Timor-Est face à l'occupant indonésien. Mattoso, ancien directeur de la Torre do Tombo à Lisbonne, a en effet travaillé à la constitution des archives de la résistance de Timor-Est. Le mot d'ordre donné par Xanana Gusmão était « Taka kapote hamutuk ho inimigo » soit « Cache toi avec le manteau de l'ennemi ». Ainsi, les habitants devaient accepter les postes et les opportunités offertes par l'occupant indonésien et se servir de ces positions pour lui résister. C'est tout un art de la dissimulation que développèrent alors les occupés. Il n'y avait donc pas d'un côté des collaborateurs et de l'autre des résistants. Tous luttaient contre l'occupant, collaboraient - ceux qui travaillaient pour l'armée indonésienne donnaient à la guérilla des munitions volées - et se servaient de tous les moyens disponibles. Enfin un entretien avec Isabel do Carmo restitue l'activité politique et la vie clandestines sous la dictature salazariste. Permanente du Parti Communiste Portugais puis fondatrice, avec Carlos Antunes, des Brigades Révolutionnaires en 1970, Isabel do Carmo raconte le quotidien des clandestins et des clandestines, possédant de faux noms, dissimulant leur véritable activité à leurs voisinages et s'ingéniant à ne pas être repérés par la police politique.

\title{
Fanvier 2008, Victor Pereira
}

\section{Fernando Ruivo \& Daniel Francisco (eds), " Poderes locais em pers- pectiva comparada ", dossier de la Revista crítica de Ciências sociais (Coimbra, Centro de estudos sociais), 77, juin 2007, 225 p.}

On ne se plaindra pas qu'une revue de sciences sociales portugaises étudie surtout des espaces non portugais, ici à propos des "pouvoirs locaux en perspective comparative ». De fait, les études publiées traitent de l'Union européenne, de l'Angleterre, de la France, de l'Italie, de l'Afrique (non lusophone) et du Mozambique. À l'exception de l'introduction (F. Ruivo \& D. Francisco) et, très partiellement, de l'article en fin de dossier (D. Francisco), le Portugal n'est pas traité. Contre le luso-localisme trop souvent présent dans les publications portugaises, le balancier

\footnotetext{
${ }^{1}$ Voir, par exemple, Dominique Pouchin, Mário Soares. Entretien avec Dominique Pouchin, Paris, Flammarion, 2002.
} 